\title{
High-Speed Friction-Stir Welding to Enable Aluminum Tailor-Welded Blanks
}

\author{
YURI HOVANSKI, ${ }^{1,5}$ PIYUSH UPADHYAY, ${ }^{1}$ JOHN CARSLEY, ${ }^{2}$ \\ TOM LUZANSKI ${ }^{3}$ BLAIR CARLSON, ${ }^{2}$ MARK EISENMENGER, ${ }^{3}$ \\ AYOUB SOULAMI,${ }^{1}$ DUSTIN MARSHALL, ${ }^{3}$ BRANDON LANDINO,${ }^{4}$ and \\ SUSAN HARTFIELD-WUNSCH ${ }^{2}$
}

\begin{abstract}
1.-Pacific Northwest National Laboratory, 902 Battelle Boulevard, Richland, WA, USA 2.-General Motors Company, Warren, MI, USA. 3.-TWB Company LLC., Monroe, MI, USA. 4.-Alcoa Inc., Farmington Hills, MI, USA. 5.—e-mail: yuri.hovanski@pnnl.gov
\end{abstract}

\begin{abstract}
Current welding technologies for production of aluminum tailor-welded blanks (TWBs) are utilized in low-volume and niche applications, and they have yet to be scaled for the high-volume vehicle market. This study targeted further weight reduction, part reduction, and cost savings by enabling tailorwelded blank technology for aluminum alloys at high volumes. While frictionstir welding (FSW) has been traditionally applied at linear velocities less than $1 \mathrm{~m} / \mathrm{min}$, high-volume production applications demand the process be extended to higher velocities more amenable to cost-sensitive production environments. Unfortunately, weld parameters and performance developed and characterized at low-to-moderate welding velocities do not directly translate to high-speed linear FSW. Therefore, to facilitate production of highvolume aluminum FSW components, parameters were developed with a minimum welding velocity of $3 \mathrm{~m} / \mathrm{min}$. With an emphasis on weld quality, welded blanks were evaluated for postweld formability using a combination of numerical and experimental methods. An evaluation across scales was ultimately validated by stamping full-size production door inner panels made from dissimilar thickness aluminum TWBs, which provided validation of the numerical and experimental analysis of laboratory-scale tests.
\end{abstract}

\section{INTRODUCTION}

The introduction of high-speed friction-stir welding (FSW) at linear velocities amenable to highvolume automotive production has the potential to revolutionize the current joining and assembly paradigm for aluminum stampings. Although laser welding has effectively enabled the welded blank market for steel, ${ }^{1-4}$ the unique metallurgical challenges associated with fusion/laser welding aluminum have prevented the adoption of laser welding technologies for aluminum blanks. ${ }^{5-8}$ This is evidenced by a significant increase in the use of more expensive riveting technologies ${ }^{9,10}$ in the assembly of stamped aluminum panels rather than use of welded blanks. An effective high-speed welding technology would enable increased weight reduction through the use of tailor-welded blanks (TWBs), which allow for part simplification, mass savings, and decoupled assembly at a reduced cost. Simply put, high-speed FSW of aluminum-welded blanks has potential to simultaneously reduce both mass and cost.

Recent announcements throughout the automotive community demonstrate an increased commitment to the overall usage and implementation of aluminum alloys for lightweight vehicle construction. With aluminum vehicles produced as early as $1902^{11}$ the use of aluminum alone in the production of automobiles is not novel, yet such intense and exclusive usage in high-volume production is unprecedented. As such, technologies that support the efficient and effective usage of aluminum alloys throughout the body-in-white are in increasingly high demand to offset the cost penalty of replacing steel with aluminum. One such technology is the use of TWBs, with a welding technique that has enabled automotive manufacturers to optimize 
material thickness, alloy, or temper to minimize the overall weight of a part. ${ }^{1,3,4,12}$ This is achieved by applying localized engineered material requirements only to specific locations rather than distributing them across entire body panels.

Tailor-welded technologies were first introduced in the United States in the 1960s and subsequently were moved to Europe by Volvo in $1979 .{ }^{13}$ At that time, blanks were produced by either electron beam or resistance mash seam welding, and only later in the 1980s did butt welding of TWBs come to fruition with the introduction of laser-welding technologies into automotive production by ThyssenKrupp (Essen, Germany). Since the 1990s, laser welding has been the preferred joining method for the production of TWBs in nearly every variety of automotive sheet steel. ${ }^{12,13}$ Several suppliers now provide laser-welded steel blanks and coils, which are available in both linear and curvilinear weld seam configurations.

For more than a decade, research related to the production of aluminum TWBs has been available. Specific studies describing the weldability of aluminum sheets have characterized numerous joining techniques including laser, electron beam, gas tungsten arc, and FSW. ${ }^{5,6,8,14-16}$ Each methodology has been shown to have specific advantages and disadvantages associated with the joining of aluminum alloys, which overall have proven much more problematic than welding automotive steel sheets. These difficulties are inherent in the physical chemistry of aluminum alloys and are most apparent when striving to manage a weld pool of molten aluminum. In this state, aluminum maintains a higher affinity for hydrogen than the surrounding atmosphere, so the association of hydrogen in the weld pool is common even with the use of traditional cover gases. Exfoliating during the solidification process, these gas particles often leave deleterious volumetric defects in their wake. ${ }^{2,6}$ This behavior is exacerbated by the presence of organic lubricants that are used transport aluminum sheets. These lubricants can become trapped on the welding edge of a sheet during the shearing process prior to welding, and therefore they are not eliminated with the use of cover gases during the welding process. As such, they are present during the fusion process, allowing the greater affinity of the molten aluminum to claim the available hydrogen atoms.

Additional difficulties have challenged traditional welding techniques, including increased thermal diffusivity when compared with ferrous materials, overall challenging solidification kinetics, molten viscosities, surface oxide, and so on. ${ }^{8,17}$ As such, the introduction of more novel welding techniques, such as FSW, has been commonly investigated; numerous researchers have reported successful weldability devoid of historic challenges. FSW, a solidstate joining process, avoids the difficulties associated with melting and solidification. Because welding occurs below the melting point, this process takes advantage of the reductions in both yield stress and flow stress to locally extrude the interface of the aluminum sheets into a seamless joint.

Comparisons between available joining technologies for production of aluminum TWBs show that postweld formability of blanks produced using solidstate FSW is generally superior to those using fusion based technologies. ${ }^{7,18}$ FSW also benefits from an ability to join without prior removal of shipping lubricants and oils, which are problematic for welding technologies that rely on localized melting and therefore require more rigorous and costly cleanliness requirements. However, FSW technology has previously lacked the ability to demonstrate high-volume production readiness because of lagging welding speeds. The production of aluminum TWBs using FSW has been available for nearly a decade for use in low-volume automotive applications ${ }^{19}$ by Audi (Herndon, VA). The welding speeds used for such production (less than one $\mathrm{m} / \mathrm{min}$ ) are generally significantly lower than travel speeds of commercial laser welding technologies, which regularly weld at speeds from $6 \mathrm{~m} / \mathrm{min}$ to $10 \mathrm{~m} / \mathrm{min}$. With few exceptions, the majority of data available for aluminum blanks produced via FSW were produced at welding speeds below $0.5 \mathrm{~m} /$ min. ${ }^{20-22}$ Several authors have examined speeds beyond $1 \mathrm{~m} / \mathrm{min} ;{ }^{14,23,24}$ however, these only cover limited thickness ratios up to 1.5:1. For application in high-volume vehicle production, welding speed is a significant factor influencing part cost. The focus of this work was to develop and characterize highspeed FSW of aluminum TWBs that could further enable greater use of mass-saving aluminum alloys in high-volume production applications.

\section{EXPERIMENTAL DETAILS}

All welding reported herein was made between dissimilar thickness AA5182-O sheets of $1.2 \mathrm{~mm}$ and $2.0 \mathrm{~mm}$ thicknesses. The details of the material properties and other weld conditions have been reported previously. ${ }^{25}$ The only constant parameter used in the development of high-speed FSW was a fixed linear velocity (welding speed) of $3 \mathrm{~m} / \mathrm{min}$. Other parameters related to welding conditions and tool designs evaluated are listed in Table I.

All weld process development was performed on a high-precision FSW machine located at the Pacific Northwest National Laboratory. The welds were oriented such that the advancing side of the weld was positioned on the thick side of the dissimilar thickness pair. Weld development panels were approximately $600 \mathrm{~mm}$ long by $225 \mathrm{~mm}$ wide, such that a welded panel had a total width of $450 \mathrm{~mm}$. Although the tool geometry varied according to the features included in Table I, all tools were based on a flat shoulder system with a concentric pin. Figure 1 displays several representative examples of tool geometries resulting from the variations noted in Table I. 


\section{Table I. Design factors for evaluating high-speed friction-stir welding}

\begin{tabular}{lcccc}
\hline Tool variations & & & \multicolumn{2}{c}{ Parameter variations } \\
\cline { 1 - 3 } \cline { 5 - 6 } Shoulder-to-pin diameter ratio (S:P) & $2.5: 1,3: 1$ & & Plunge depth (mm) & $1.85,2.00$ \\
Pin length (mm) & $1.5,1.75,2.0$ & & Tool tilt angle (pitch) & $1^{\circ}, 0^{\circ}$ \\
Pin features & Taper, flats, threads & & Tool roll angle & $3.82^{\circ}$ (tangent), $3^{\circ}$ \\
Shoulder features & One scroll, two scrolls & & Rotational velocity (rpm) & $1100,1500,1950$ \\
\hline
\end{tabular}

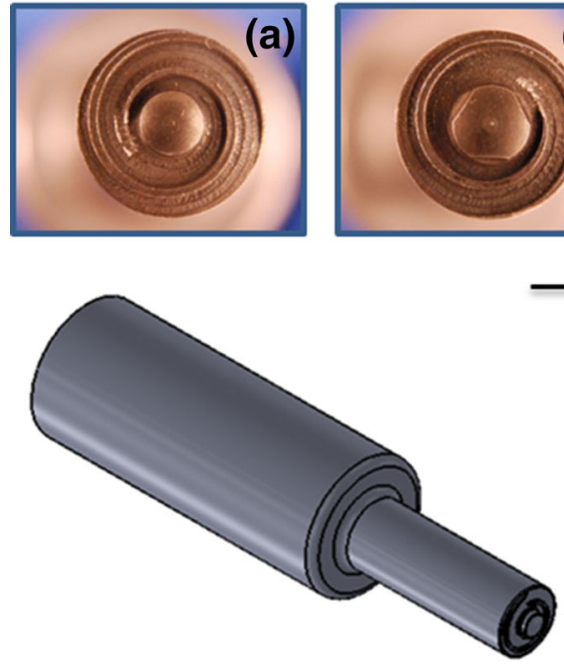

(e)

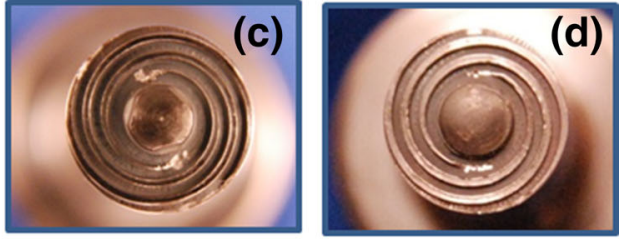

$12 \mathrm{~mm}$

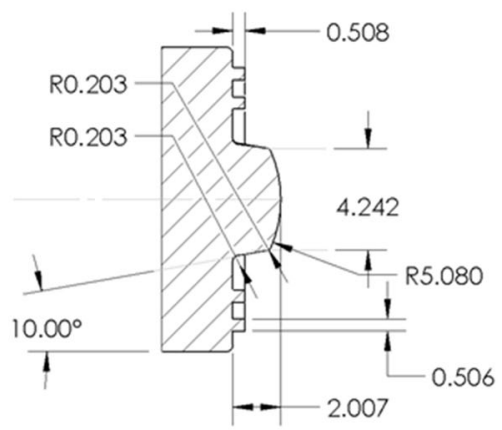

(f)

Fig. 1. End views of representative tools used for the experiments. (a) Tapered pin, single scrolled shoulder, shoulder-to-pin diameter ratio $S / P=3$. (b) Pin with three flats, single scrolled shoulder, $S / P=2.5$. (c) Pin with three flats, double scrolled shoulder, $S / P=3$. (d) Threaded pin, double scroll, $S / P=3$. (e) Isometric view of the tool. (f) Schematic cross-section of a $2 \mathrm{~mm}$ long pin with three flats, double scrolled shoulder with $S / P=3$.

The tensile properties and probabilistic formability limits of the welded material were established by evaluating a statistically significant population of transverse and longitudinal tensile specimens. As FSWs produced in dissimilar thickness cannot be evaluated using traditional tensile specimens, Fig. 2 illustrates the representative geometries of tensile coupons used to evaluate the mechanical properties and determine the conditions of safe strain for the welded coupons.

Initial postweld formability was evaluated using a series of Interlaken servopresses (Interlaken Technology, Chaska, MN) to perform limiting dome height (LDH) tests of the welded dissimilar thickness blanks. All testing was performed with a 101.6$\mathrm{mm}$ diameter spherical punch at a rate of $10 \mathrm{~mm} /$ min. A Correlated Solutions digital image correlation (DIC) system (Correlated Solutions, Columbia, SC) was used to monitor strain development from the top side of the welded panel while the LDH punch applied pressure to the bottom. This setup

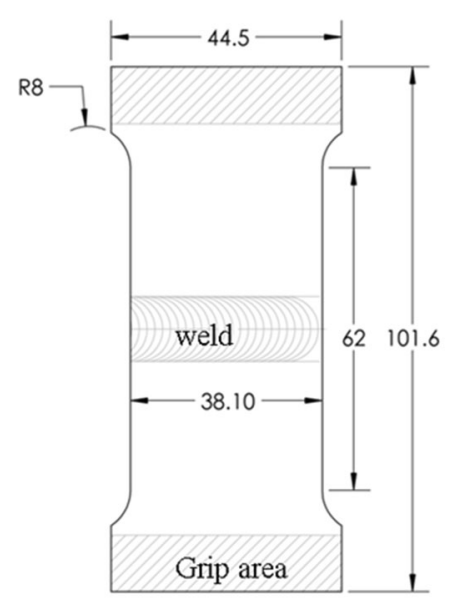

Transverse sample

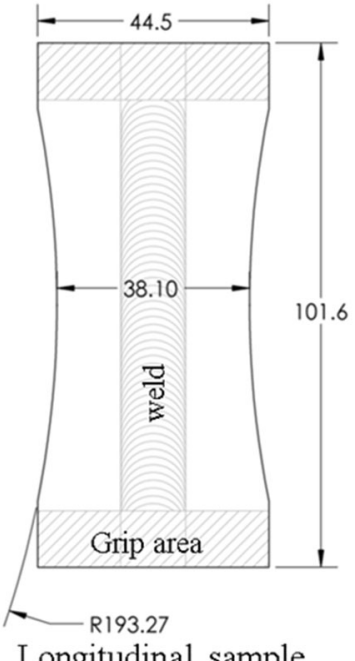

Longitudinal sample
Fig. 2. Representative geometries for tensile coupons of welded aluminum TWBs. 

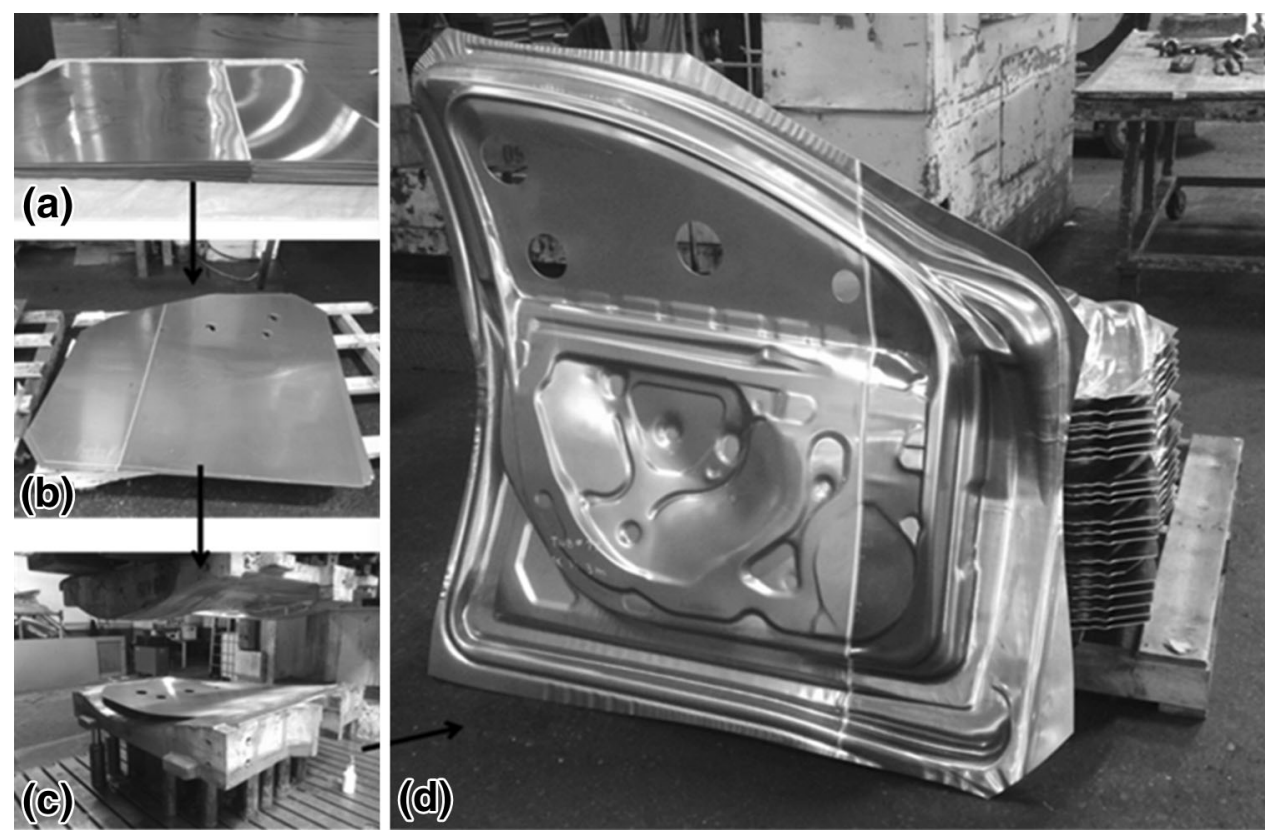

Fig. 3. Prototypical door inner panel stamped from AA5182-O TWB including (a) a stack of as-welded TWBs, (b) laser-trimmed TWB, (c) TWB positioned in the stamping die, and (d) stamped differential gauge aluminum door inner panel.

allowed for height and pressure measurement from the press to be correlated with strain measurements of the dissimilar thickness specimen. As a means of validating finite-element models, $\mathrm{LDH}$ testing was also performed on aluminum panels that had been machined from monolithic sheets of AA5182-O into representative TWB geometries with thickness ratios ranging from 1:1 to 3:1. The machined slope of the transition between thick and thin sides of each monolithic specimen corresponded to the FSW tool shoulder diameter of $12.7 \mathrm{~mm}$.

\section{RESULTS AND DISCUSSION}

There are several important areas to discuss in relation to the development of a high-speed FSW process that enables high-volume production of aluminum TWBs. A comparative look at how the welding process evolved to accommodate high speed development is a natural starting point for a discussion of production-focused welding parameters and tooling. Next an examination of the results of the statistical design of experiments data that directed the selection of final parameters and tooling is warranted. As these results are directly connected to the mechanical properties and postweld formability of the welded panels, a discussion of the relevant statistical analysis will naturally lead to a more focused consideration of the formability of the aluminum TWB. This in turn allows for an exploration of how actual formability compared with the simulated results. These analyses ultimately support how the technology moved from laboratoryscale testing and simulation to the prototypical stamped components presented in Fig. 3.
Traditionally, FSW tools used in aluminum alloys were focused on geometries that are effective at welding speeds below $1 \mathrm{~m} / \mathrm{min}$. Although variations of tool designs are used to tailor properties for specific aims, a general rule of thumb for FSW aluminum sheet is to use a threaded tool tilted at an angle of $3^{\circ}$ normal to the workpiece such that the heel of the tool sits deeper into the material than the leading edge. ${ }^{2,26,27}$ Unfortunately, the conventional wisdom presented in more than a decade of literature was less effective when translated to high welding velocities. Initial welding trials demonstrated that tool tilts greater than $1^{\circ}$ increased tool drag as demonstrated by increased forces in the welding direction. This produced deleterious effects of both surface quality and overall distortion in the welded panel. Additionally, higher tool tilt was shown to produce greater weld flash and reduced thickness of the weld nugget because of deeper engagement of the shoulder at the trailing edge. The tool tilts listed in Table I were selected to avoid any reduction in thickness throughout the weld region, to minimize welding forces and weld flash, and to reduce potential sheet distortion. Representative roughness data presented in Fig. 4 show a smooth weld crown that may be used without any subsequent machining operation.

The tool roll angles defined in Table I were set to accommodate two specific positioning paradigms. While previously reported studies ${ }^{23}$ focused on using tools with convex shoulders and higher tilt angles to avoid inducing any tool roll, such strategies do not permit thickness ratios much beyond 1.5:1. Because this work was focused on greater thickness ratios, the introduction of a roll angle 


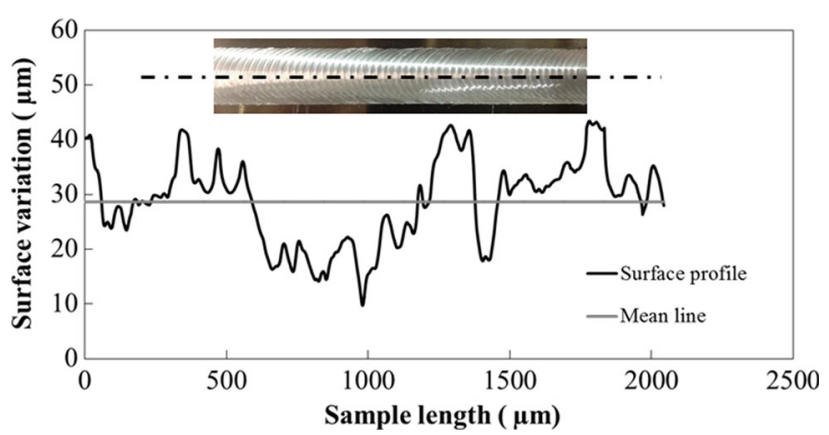

Fig. 4. Plot showing the variation in surface roughness associated with the weld surface along the centerline of the weld as indicated by the dashed line along the inlaid image of the weld.

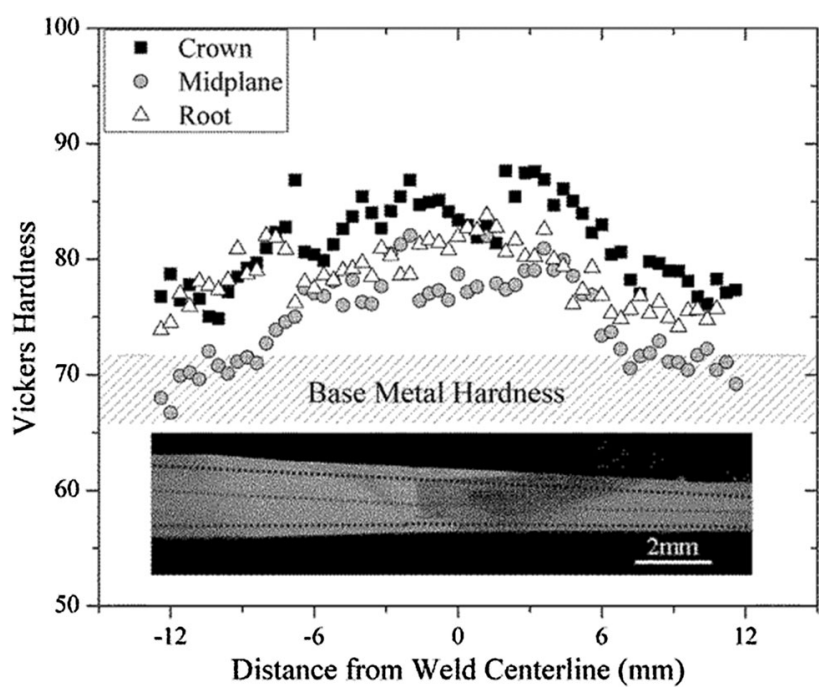

Fig. 5. Microhardness data from a high-speed $(3 \mathrm{~m} / \mathrm{min})$ friction-stir weld made in AA5182-O. Etched macro cross-section of the weld shows defect-free and flash-free weld region.

discussed by von Strombeck et al. ${ }^{14}$ ultimately allowed for welding across sheets with greater than a $2: 1$ thickness ratio. The two approaches investigated herein provide for conditions noted as tangent and less-than-tangent to the normal of the abutting faces. In the case of the tangent setup, the edges of the 12.7-mm-diameter shoulder just contacts the surfaces of each of the two sheets such that a weld is produced that exactly transitions from the surface of the thin sheet to the surface of the thick sheet over a $12.7-\mathrm{mm}$ (diameter of shoulder) distance. For the less-than-tangent case, the tool is slightly rolled toward the thick sheet with the intent to slightly pad the final welded section of the thin sheet. While the differences in the roll angles are less than a single degree $\left(3.82^{\circ}\right.$ (tangent) versus $\left.3^{\circ}\right)$, these results suggest that the tangent condition provides a better overall welding condition. When evaluated with interactions of other factors, the tangent condition was better for higher rotational velocities, lower tool tilt angles, and more shallow plunge conditions that prevented the shoulder from plunging excessively into the surface. Figure 5 presents the microhardness data from a representative weld, showing an expected rise in hardness associated with the work-hardenable alloy. A corresponding macrograph in Fig. 5 shows a defect-free weld with no flash.

A Taguchi design of experiments approach was executed in Minitab (Minitab Inc., State College, PA) to systematically investigate the effects of various welding factors on resulting weld quality and mechanical properties. The Taguchi method used a structured and organized dataset to define relationships between process factors and responses with a significantly reduced number of experiments compared to full factorial runs. A total of 36 runs were prescribed by Minitab ${ }^{\mathrm{TM}}$ which resulted in a 33 unique tool designs used with different combinations of weld control variables listed in Table I. An evaluation of weld parameters as presented in Figs. 6 and 7 was based on weighted and combined results that included transverse tensile strength, ductility, biaxial formability, surface roughness, and extent of weld flash. These results where then normalized to rate them from zero to one for ease of comparison. A more detailed explanation of this Taguchi-based design of experiments was provided previously. ${ }^{25}$ These data present the outline for justification of which welding trends provided the best high-speed FSW solution and allow for combining both welding parameters and tool design into a single solution matrix. The main effects alone showed that higher rotational velocities of $1500 \mathrm{rpm}$ and $1950 \mathrm{rpm}$ were more likely to produce good welds, but also suggested that there was little difference above the midpoint. Tapered pins with flat features were clearly more beneficial than threads at a welding speed of $3 \mathrm{~m} / \mathrm{min}$, which is a change from the conventional wisdom for welding aluminum alloys. Additionally, the following conclusions can be reached from careful study of the data: Some degree of tool tilt was better than none, tool roll angles leading to a tangent condition showed better overall results than the less-than-tangent condition, the smaller pin diameter leading to the low condition for the shoulder/pin diameter ratio was significantly better, and longer pin lengths were better for welding the sheet thicknesses included herein. Although these main effects are obvious, the interactions among different welding parameters become important in ultimately defining the best joining solution. This point is demonstrated most effectively by studying the interaction between plunge depth and pin length. For both the $1.5 \mathrm{~mm}$ and $1.75 \mathrm{~mm}$ pin lengths, the shallow plunge condition $1.85 \mathrm{~mm}$ was preferred. However with the $2.0 \mathrm{~mm}$ pin length, the trend not only completely reversed, but also this combination demonstrated nearly the greatest combined effect of any factors evaluated herein.

Ultimately, the evaluation of the statistical factors and interactions presented in Figs. 6 and 7 enabled selection of high-speed FSW parameters 

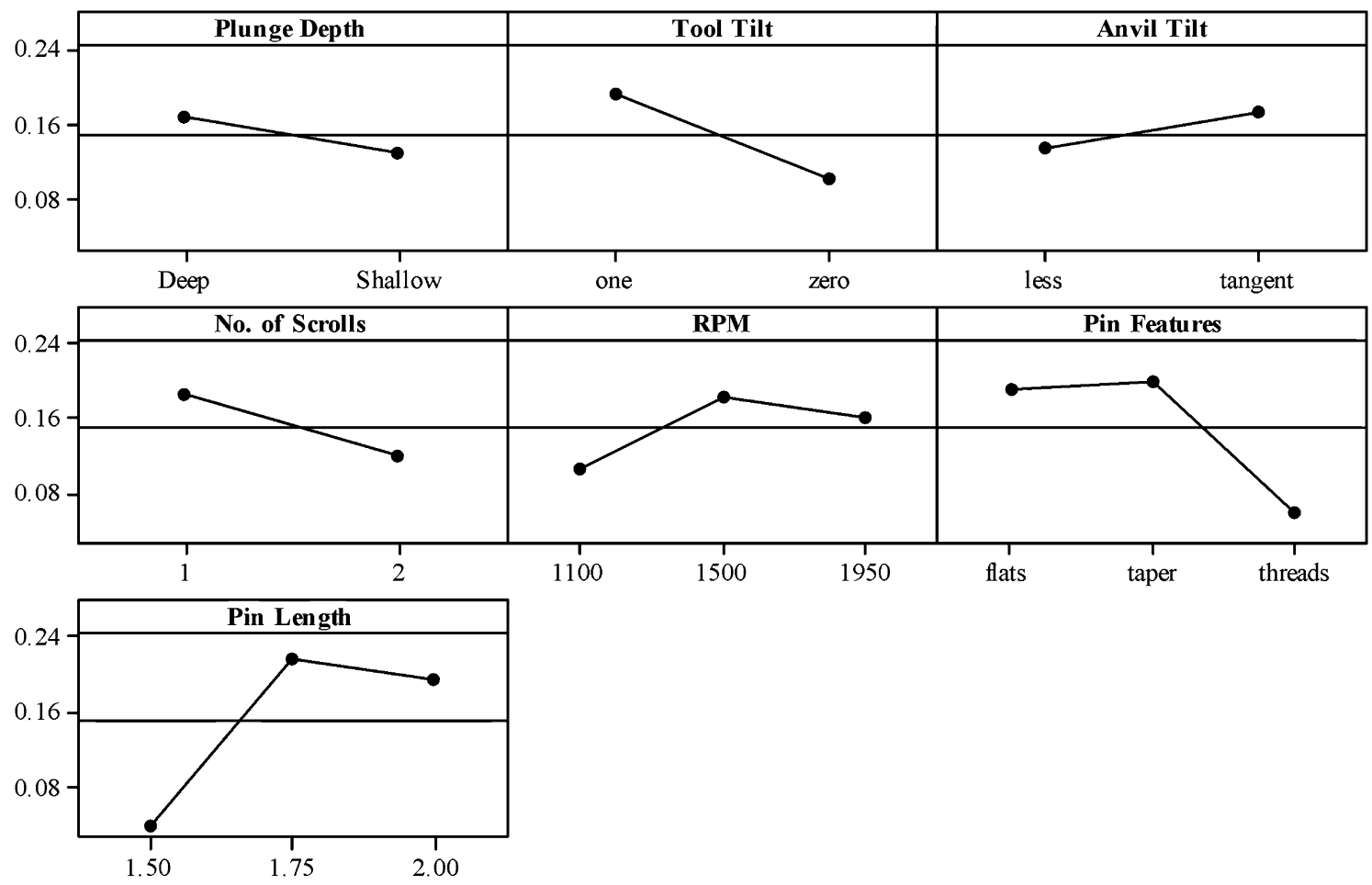

Fig. 6. Plots showing the influence of each individual factor (tool feature or process parameter) on resulting weld response in the design of experiment approach. ${ }^{25} \mathrm{~A}$ higher number represents a greater fit with the measured responses of tensile strength, formability, surface roughness, and minimal weld flash.

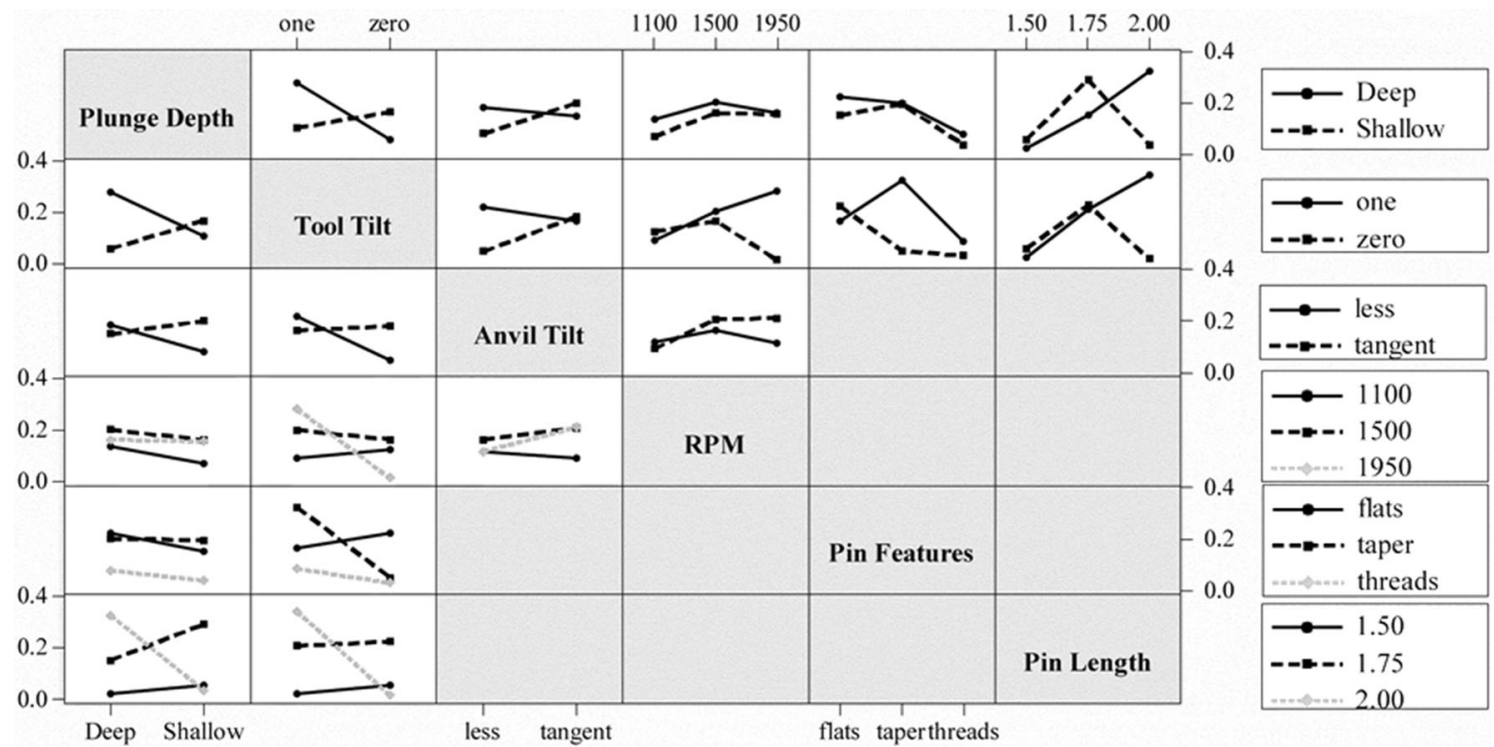

Fig. 7. Interaction plots showing the influence of the combined effects of factors in the design of experiment approach used to evaluate the combined influence of tool geometry and process parameters on enabling high-speed FSW of aluminum TWBs. A higher number represents a greater combined fit with the measured responses of tensile strength, formability, surface roughness, and minimal weld flash.

and tooling that minimized weld flash, maximized strength and formability, and yielded repeatable and consistent weld surfaces and properties. These welds were then scrutinized further to determine their probabilistic fracture properties.
To provide guidelines for an allowable forming limit of the friction-stir welded aluminum TWB a probabilistic forming limit diagram (FLD) for the TWB was developed. A formability envelope for the TWB that included the effects of the weld region 
was established using a combination of the Marciniak and Kuczynski method (M-K method) ${ }^{28}$ and experimentally measured localization strains in the weld material. The $\mathrm{M}-\mathrm{K}$ method hypothesizes that preexisting geometric imperfections in sheet material are the sites of eventual strain localization and fracture during biaxial stretching. The region outside of the imperfection is assumed to be homogeneous. With this assumption, an FLD is calculated by numerically applying loads on the sheet and tracking strains in both imperfect and homogeneous regions. The fracture occurs when the imperfect region accumulates strain at a much higher rate than the homogeneous region. See the discussion by Davies et al. ${ }^{29}$ for details.

Imperfection levels for a TWB population were determined from a series of tensile tests performed on weld samples at both longitudinal and transverse orientation (30 samples each). The geometric details for the tensile tests are included in Fig. 2. Major and minor strains prior to crack initiation were obtained from each sample using a DIC technique. The level of imperfection that corresponded to measured major and minor strain for each sample was calculated using the $\mathrm{M}-\mathrm{K}$ method. Figure 8 presents the safe strains and corresponding imperfection levels $f$ obtained for each of 30 transverse tensile specimens. This process was carried out for both transverse and longitudinal tensile specimens to determine the level of strain just prior to incipient necking. A statistically based level of imperfection was then assigned to the TWB population assuming Weibull probability distribution as presented in Fig. 9. These calculations were useful in determining a FLD for the overall dissimilar thickness welded blank with an acceptable fracture rate of 1 part per 1,000. This reduced FLD, shown in Fig. 10 (gray line), compared with the FLD from the monolithic material (black line), was used as one of the deterministic fracture criteria employed in evaluating the formability of the as-welded materials via finite-element analysis (FEA). The commercial finite-element software Abacus Explicit (Dassault Systèmes Americas Corp., Waltham, MA) was used to model sheet deformation behavior under a hemispherical die to simulate $\mathrm{LDH}$ tests. A two-dimensional axisymmetric model was used to simulate an aluminum sheet of various thickness combinations. The punch and die were modeled as analytical rigid surfaces, whereas the aluminum sheet was modeled of shell elements with a thickness offset from the die direction.

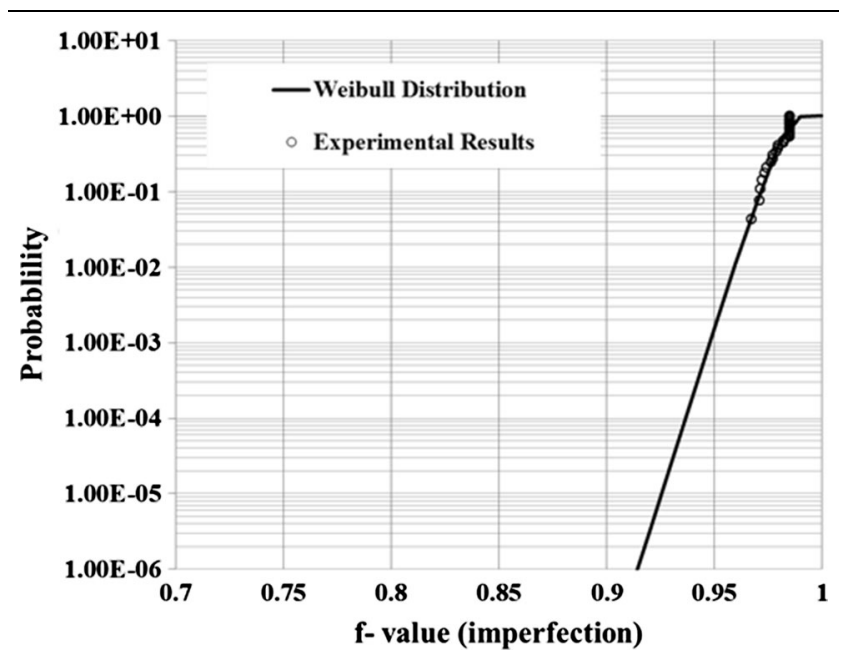

Fig. 9. Plot of the Weibull probability distribution of individual imperfection levels $(f)$ calculated on the basis of a theoretical FLD using the $\mathrm{M}-\mathrm{K}$ method. This graph was utilized to determine the safe level of strain for the desired fracture rate.

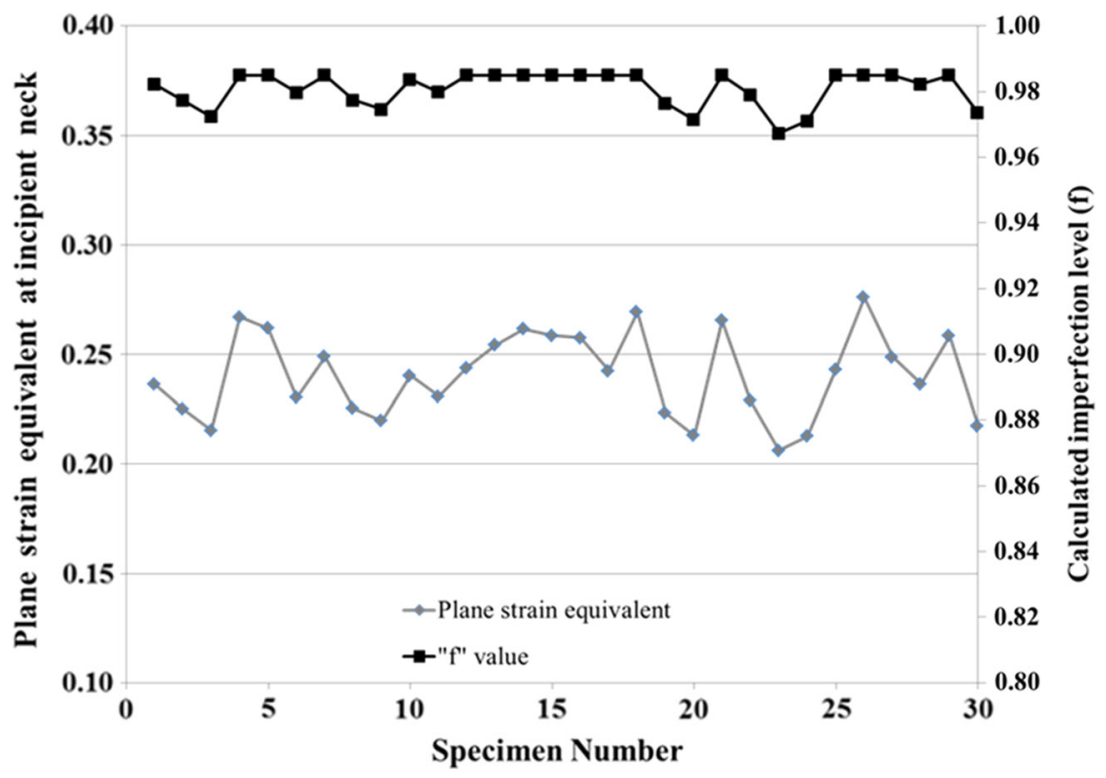

Fig. 8. Plot showing the variation in equivalent strain prior to the onset of through-thickness necking in transverse tensile samples in conjunction with the calculated level of imperfection for each tested sample as determined using the M-K method. 


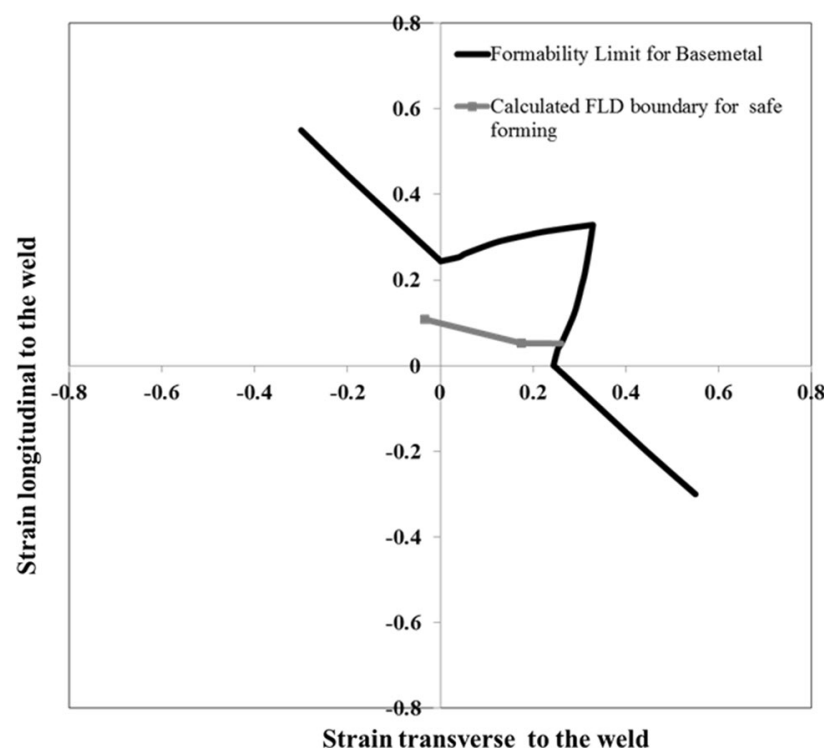

Fig. 10. Comparative plot of the monolithic FLD of AA5182-O with the reduced FLD for safe-forming plot in gray.

Table II. Comparison of simulated dome heights with various fracture criteria for dissimilar thickness (2-1 mm) aluminum-welded blanks with a smooth tapered transition at the weld

Limiting dome heights (mm)

\begin{tabular}{lll}
\hline Isotropic & Anisotropic & Anisotropic FLD \\
& 14.75 &
\end{tabular}

Formability simulations of the LDH test were produced with three separate fracture criteria. As the AA5182 material is a work-hardening alloy, initial isotropic material properties associated with base metal properties were used to simulate how the tapered geometry and differences in sheet thicknesses influenced the overall welded blank formability. Table II displays the comparative results of the conditions simulated with isotropic and anisotropic properties. The anisotropic conditions provided unique properties of the welded material for that section of the model, and simulated LDH based on two distinct fracture criteria. The first was a condition in which any portion of the simulated dome achieved an equivalent strain exceeding $18 \%$, which was comparable with the tensile data obtained from the welded sheet and monolithic materials. The second condition used the statistically determined FLD to impose unique material properties in the welded material based on the probabilistic performance of the welded panels as measured via the longitudinal and transverse tensile specimens discussed previously. This statistical

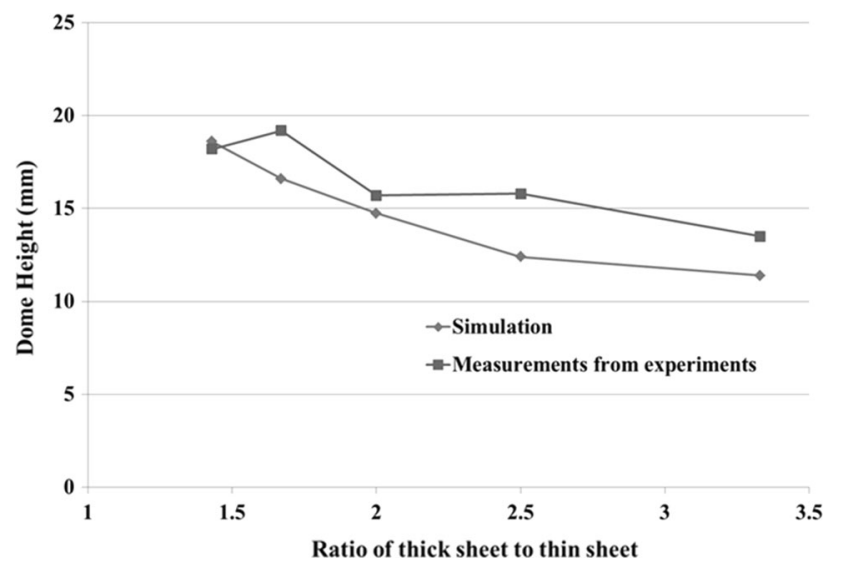

Fig. 11. Comparative plot of simulated and actual measurement of $\mathrm{LDH}$ for various sheet thickness ratios.

approach relies on calculating a level of imperfection associated with the introduction of a weld into otherwise monolithic materials, which have their own unique inherent level of imperfection.

As the predictions based on the statistically determined FLD exhibited the lowest available $\mathrm{LDH}$ of any of the simulated results, it is noteworthy to evaluate these findings. The FLD fracture criterion was designed to establish a limit of strain based on the probabilistic performance of the welded material, which would assure that no fractures would occur when applying this criterion. As such, the overall predicted "safe" dome height should be notably less than an actual test sample. The calculation of the level of imperfection that enabled this statistical determination essentially requires that a safety margin is designed into the fracture criterion to avoid finding statistical variation in practice that would be outside of the predicted values.

The comparative plot of simulated and actual dome heights in Fig. 11 presents how finite-element modeling in Abaqus Explicit compared with the dome heights of specimens that had been machined from monolithic material. In all cases, the dome height simulated via FEA underpredicted the actual performance of the machined specimens. In comparing the actual FSW panels of AA5182-O in thicknesses of $1.2 \mathrm{~mm}$ and $2.0 \mathrm{~mm}$ (a thickness ratio of $1.66: 1$ ), the monolithic machined sheets achieved a dome height of $19.2 \mathrm{~mm}$, with a simulated height of $16.6 \mathrm{~mm}$. The actual welded specimens achieved an average dome height of $18.3 \mathrm{~mm}$, suggesting that the welds did reduce actual monolithic performance. Nevertheless, although the simplified FEA performed herein is adequate to represent trends, it was not capable of accurately predicting the actual performance. It is hoped that greater sophistication in simulating the variation of material properties along with the functional changes in properties under strain will provide increased accuracy. The FEA presented herein seemed to accurately represent the geometric 
discontinuities introduced by joining dissimilar thickness sheets as shown with the trends predicted across a variation in thickness ratio.

\section{CONCLUSION}

While welding technologies for production of aluminum TWBs currently have yet to be scaled for the high-volume vehicle market, the results of this study demonstrate that further weight reduction, part reduction, and cost savings may be achieved using high-speed FSW to join aluminum TWBs at high volumes. FSW, which has traditionally been applied at linear velocities less than $1 \mathrm{~m} / \mathrm{min}$, was demonstrated to be effective for producing dissimilar thickness aluminum TWBs at linear velocities of $3 \mathrm{~m} / \mathrm{min}$. Traditional weld parameters developed at low-to-moderate welding speed did not directly translate to high-speed linear FSW. However, judicious use of a statistical design of experiment approach helped to establish effective functional relationships between tool geometry and process parameters, thus leading to optimized FSW parameters and tool design to enable high-volume production of TWBs with acceptable formability characteristics.

With an emphasis on overall weld quality, aluminum TWBs were evaluated for postweld formability using a combination of numerical and experimental methods. Simulation of postweld formability was evaluated with three distinct fracture criteria, which were subsequently compared with as-welded and machined dissimilar blanks. These comparisons demonstrated that finiteelement modeling provided useful data to trend the effective formability differences associated with the geometric discontinuity created by a dissimilar thickness joint. For thickness ratios ranging from 1.5 to 3.3 , the simulation provided a conservative estimate of the changes in dome height during $\mathrm{LDH}$ testing of the dissimilar thickness blanks.

\section{ACKNOWLEDGEMENTS}

The authors gratefully acknowledge funding from the Department of Energy-EERE-Vehicle Technology Office's Lightweight Materials Program under the direction of Mr. William Joost. The data shared herein was developed as part of a collaborative effort between the Pacific Northwest National Laboratory, General Motors Company, TWB Company, and Alcoa Inc.

\section{NOTICE}

This manuscript has been authored by Battelle Memorial Institute under Contract No DE-AC0576RL01830 with the U.S. Department of Energy. The U.S. government retains, and the publisher by accepting this article for publication, acknowledges that the U.S. government retains a nonexclusive, paid-up, irrevocable, worldwide license to publish or reproduce the published form of this manuscript, or allow others to do so, for U.S. government purposes.

\section{REFERENCES}

1. B. Kinsey and X. Wu, Tailor Welded Blanks for Advanced Manufacturing (New York: Elsevier, 2011).

2. E. Assuncao, L. Quintino, and R. Miranda, Int. J. Adv. Manuf. Technol. 49, 123 (2010).

3. R.J. Pallett and R.J. Lark, J. Mater. Process. Technol. 117, 249 (2001).

4. B. Rooks, Assem. Autom. 21, 117 (2001).

5. S. Das, Adv. Mater. Process. 157, 41 (2000).

6. R.W. Davies, H.E. Oliver, M.T. Smith, and G.J. Grant, JOM 51, 46 (1999)

7. R.W. Davies, M.T. Smith, H.E. Oliver, M.A. Khaleel, and S.G. Pitman, Metall. Mater. Trans. A 31, 2755 (2000).

8. H.R. Shakeri, A. Buste, M.J. Worswick, J.A. Clarke, F. Feng, M. Jain, and M. Finn, J. Light Met. 2, 95 (2002).

9. R. Truett, A riveting tale: How will Ford build the aluminum F-150? Automotive News, 28 April 2014.

10. E. Stephens, G. Grant, R. Davies, S. Wazny, L. Kaunitz, B. Fulbright, and D. Waldron, Paper presented at the Proceedings of the 2005 SAE World Congress (Detroit, MI, 11-14 April 2005).

11. D.E. Horvath, Use of aluminum in autos debuted in 1902, AutoGiftGarage.com, 28 February 2014.

12. M. Merklein, M. Johannes, M. Lechner, and A. Kuppert, J. Mater. Process. Technol. 214, 151 (2014).

13. H. Mohrbacher, Paper Presented at the 9th International Conference on Sheet Metal (2001), pp. 305-312.

14. A. Von Strombeck, S. Sheikhi, and J.F. Dos Santos, Paper Presented at the 4th International Friction Stir Welding Symposium (2003).

15. B. Kinsey, V. Viswanathan, and J. Cao, Paper Presented at the Proceedings of the SAE 2001 World Congress (Detroit, MI, 5-8 March 2001).

16. M.C. Stasik and R.H. Wagoner, Aluminum and Magnesium for Automotive Applications, ed. J.D. Bryant and D.R. White (Warrendale, PA: TMS, 1996), p. 69.

17. T.A. Barnes and I.R. Pashby, J. Mater. Process. Technol. 99, $62(2000)$.

18. Y. Hovanski, J. Carsley, B. Carlson, S. Hartfield-Wunsch, and S.A.E. Int, J. Mater. Manuf. 7, 537 (2014).

19. http://www.riftec.de/en/friction-stir-welding/fsw-the-applica tions/.

20. D. Kim, W. Lee, J. Kim, C. Kim, and K. Chung, Int. J. Mechan. Sci. 52, 612 (2010).

21. C. Leitão, B. Emílio, B.M. Chaparro, and D.M. Rodrigues, Mater. Des. 30, 3235 (2009).

22. W. Lee, K.H. Chung, D. Kim, J. Kim, C. Kim, K. Okamoto, R.H. Wagoner, and K. Chung, Int. J. Plast. 25, 1626 (2009).

23. G. Grant, R. Davies, E. Stephens, S. Wazny, L. Kaunitz, and D. Waldron, Paper Presented at the Proceedings of the 2005 SAE World Congress (Detroit, MI, 11-15 April 2005).

24. Y.S. Sato, Y. Sugiura, Y. Shoji, S.H.C. Park, H. Kokawa, and K. Ikeda, Mater. Sci. Eng. A 369, 138 (2004).

25. Y. Hovanski, P. Upadhyay, S. Pilli, B. Carlson, J. Carsley, S. Hartfield-Wunsch, and M. Eisenmenger, Light Metals, ed. J. Grandfield (New York: Wiley, 2014), pp. 265-270.

26. M.P. Miles, B.J. Decker, and T.W. Nelson, Metall. Mater. Trans. A 35A, 3461 (2004).

27. K. Chung, W. Lee, D. Kim, J. Kim, K.H. Chung, C. Kim, K Okamoto, and R.H. Wagoner, Int. J. Solids Struct. 47, 1048 (2010).

28. Z. Marciniak and K. Kuczyński, Int. J. Mechan. Sci. 9, 609 (1967).

29. R.W. Davies, G.J. Grant, H.E. Oliver, M.A. Khaleel, and M.T. Smith, Metall. Mater. Trans. A 32, 275 (2001). 